\title{
Implementasi Teori Keperawatan Sebagai Upaya Peningkatan Kualitas Pelayanan Keperawatan
}

\author{
Fitri Arofiati1 \\ 1Magister Keperawatan Universitas Muhammadiyah Yogyakarta, \\ Jalan Brawijaya Tamantirto Kasihan Bantul \\ Magister Keperawatan Universitas Muhammadiyah Yogyakarta, \\ Jalan Brawijaya Tamantirto Kasihan Bantul 55183, Telp. 274387656, 08164224386 \\ Email: fitri.arofiati@umy.ac.id \\ DOI: $10.18196 / p p m .39 .127$
}

\begin{abstract}
Abstrak
Perawat yang bekerja di rumah sakit dalam melakukan tindakan keperawatan belum melakukan berdasarkan teori keperawatan, namun lebih banyak bersifat kebiasaan. Hal ini membuat tidak optimalnya kualitas asuhan keperawatan yang diberikan dan perawat tidak memahami aplikasi konsep teori dalam memberikan asuhan keperawatan. Pengabdian masyarakat ini dilakukan di RSUP Prof. dr, R. D. KANDOU MANADO, sebagai salah satu upaya untuk meningkatkan kapasitas perawat dalam melakukan implementasi keperawatan sesuai dengan teori keperawatan. Proses kegiatan ini dilakukan dengan mengintegrasi kegiatan tri dharma PT yaitu pengabdian masyarakat dalam konsep pembelajaran berupa seminar keperawatan yang diikuti oleh 100 perawat. Pelaksanaan pengabdian masyarakat yang dilakukan adalah dengan pelaksanaan metode pembelajaran mentoring pada pertemuan terakhir tentang aplikasi teori keperawatan dalam asuhan keperawatan di RS oleh mahasiswa dan dilakukan penilaian menggunakan rubrik yang telah ditetapkan oleh dosen pembimbing dan dihitung sebagai salah satu bagian proses penilaian blok. Sebelum dan setelah kegiatan dilakukan tes untuk mengetahui pengetahuan perawat dalam mengimplementasikan teori keperawatan. Hasil pengabdian masyarakat menggambarkan peningkatan pengetahuan perawat dalam meningkatakan kualitas asuhan keperawatan melalui implementasi teori keperawatan. Luaran dari pengabdian masyarakat ini adalah buku monograf yang memiliki ISBN dan tersertifikasi HKI, hasilnya dipublikasikan di jurnal atau prosiding seminar nasional.
\end{abstract}

Kata Kunci: Teori keperawatan, kualitas asuhan keperawatan

\section{Pendahuluan}

Keperawatan adalah suatu bentuk pelayanan profesional yang merupakan bagian integral dari pelayanan kesehatan didasarkan pada ilmu dan kiat keperawatan, berbentuk pelayanan biopsiko-sosio-spiritual yang komprehensif. Keperawatan profesional diterapkan dengan mengaplikasikan ilmu dan teori keperawatan dalam praktik, Pendidikan, dan riset keperawatan. Ilmu keperawatan dalam memenuhi tuntutan dan tekanan masyarakat harus dikembangkan berdasarkan pemahaman pada konsep dan teori keperawatan. Pengembangan berdasarkan teori ini dimaksudkan agar dalam pengaplikasiannya tidak menyimpang dari model atau konsep keperawatan yang sudah ada.

Saat ini RSUP Prof. Kandou resmi beroperasi sebagai rumah sakit umum kelas tipe A, setelah tahun 2015 menerima Surat Keputusan Menteri Kesehatan RI nomor HK.02.03./I/0824/2015 dan menjadi rumah sakit pendidikan bagi profesi kesehatan termasuk perawat. Rumah sakit ini memiliki 6 layanan unggulan yaitu layanan bedah spine (orthopedic), layanan bedah vaskuler, layanan neonatal intensive care unit (NICU), layanan endoscopic ultrasound, layanan kanker terpadu dan layanan jantung terpadu. Jumlah perawat keseluruhan sekitar 700 orang dengan latar belakang pendidikan mulai diploma sampai magister, dan sebagian besar berasal dari wilayah Sulawesi. Sebagai rumah sakit pendidikan maka proses pelayanan keperawatan juga selalu dikaitkan secara langsung dengan perkembangan teori keperawatan yang ada. Permasalahan yang ditemukan adalah bahwa sebagian besar perawat dalam melakukan tindakan keperawatan belum mengetahui teori keperawatan yang sedang diterapkan sehingga pengembangan aplikasi maupun inovasi keperawatan yang dilakukan belum kelihatan. Hal ini mengakibatkan proses interaksi antara perawat dengan pasien, perawat dengan perawat, perawat dengan tenaga kesehatan lainnya menjadi kurang intensif. Pada tahun akademik 2019/2020 ini sekitar 24 mahasiswa Magister keperawatan UMY berasal dari Manado 
dan sekitarnya (48\%) sebagai bagian dari pengembangan program pendidikan menggunakan system blended learning, 18 diantaranya berasal dari RSUP Prof. Kandou. Proses pembelajaran menggunakan beberapa metode diantaranya tutorial, klasikal, field site teaching, e-learning dan mentoring dengan teknik evaluasi yang sesuai.

Pengembangan aplikasi teori keperawatan menjadi salah satu tugas mahasiswa di Prodi Magister keperawatan di tahun pertama, Blok 1 Basic Nursing Science. Pada proses pembelajaran yang dilakukan, mahasiswa diberikan penugasan untuk melakukan analisis situasi di area pelayanan keperawatan tentang aplikasi teori keperawatan yang telah digunakan dan ditindaklanjuti dengan desiminasi hasil analisisnya di media massa baik online maupun cetak. Proses pembimbingan dilakukan dengan menggunakan metode mentoring dengan pembagian mahasiswa dalam kelompok kecil (7-8 mahasiswa). Mentoring dilakukan baik secara tatap muka maupun online, dengan 4 kali pertemuan termasuk ujian (presentasi akhir dan diseminasi di media massa). Sesuai dengan konsep KKNI 2012 maupun pengembangan sistem akreditasi menggunakan 9 kriteria, maka integrasi proses kegiatan tri dharma perguruan tinggi menjadi salah satu prioritas kegiatan yang harus dilakukan. Sehubungan dengan hal tersebut, pengabdi mencoba mengintegrasikan proses pembelajaran mentoring dengan kegiatan pengabdian masyarakat, yaitu presentasi akhir mahasiswa yang menjadi salah satu penilaian dilakukan dengan metode seminar sebagai upaya peningkatan kapasitas perawat dalam pemberian asuhan

keperawatan. Seminar ini diselenggarakan di RSUP Dr. R.D Kandou dimana sebagian besar mahasiswa Manado bekerja, bekerjasama dengan pihak rumah sakit. Dilakukannya kegiatan ini maka diharapkan perawat pelaksana di rumah sakit akan memahami konsep teori keperawatan dan aplikasinya di berbagai setting layanan keperawatan/ menunjukkan peningkatan kapasitas dalam pemberian asuhan keperawatan.

Permasalahan yang dihadapi oleh perawat pelaksana yang bekerja di rumah sakit adalah belum memahami aplikasi konsep teori keperawatan dalam pemberian asuhan keperawatan yang komprehensif sehingga dibutuhkan kerjasama dengan mitra pendidikan agar kualitas asuhan keperawatan meningkat/lebih baik. Kapasitas perawat dalam mengimplementasikan teori keperawatan pada pemberian asuhan keperawatan merupakan faktor yang sangat penting. Hal ini akan menjadi tolak ukur kualitas pelayanan keperawatan yang berimbas pada kualitas pelayanan kesehatan secara umum di RS.

\section{Metode Pelaksanaan}

Pengabdian masyarakat ini dilakukan dengan mengintegrasikan proses pembelajaran tahun pertama Blok Basic Nursing Science dengan metode mentoring yang keempat (tahap penilaian akhir). Kegiatan yang dilakukan adalah dengan mengadakan seminar keperawatan yang akan diselenggarakan di RSUP Dr. R.D Kandou (tempat kerja mahasiswa Magister Keperawatan). 


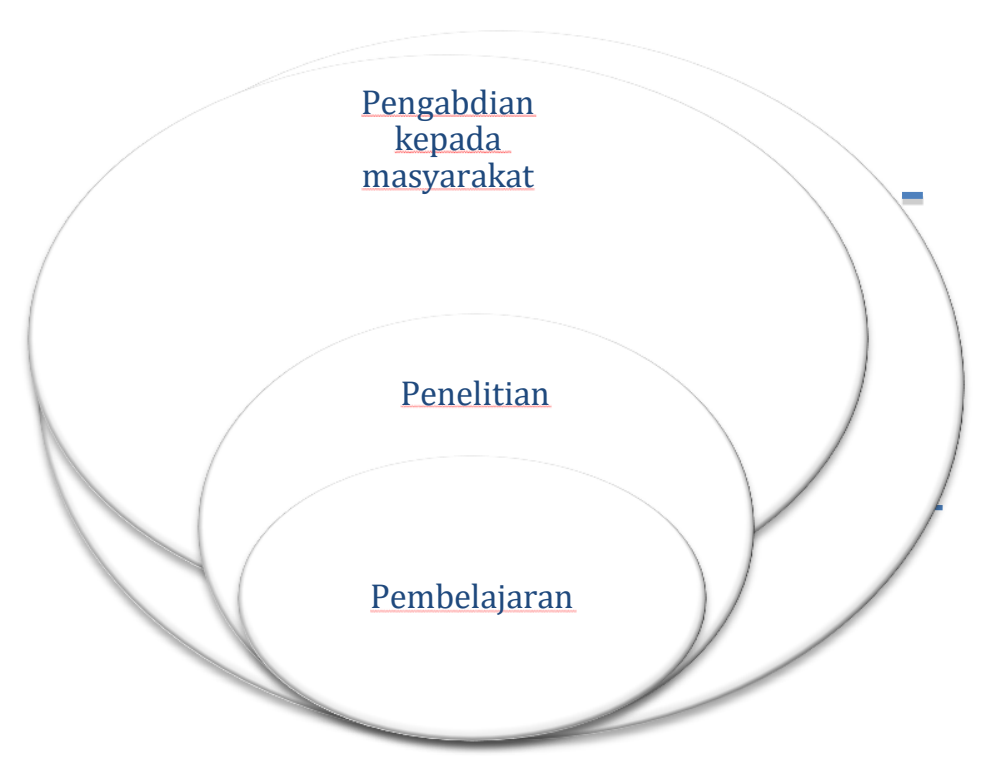

Desiminasi hasil analisis aplikasi teori keperawatan dalam pelayanan keperawatan di rumah sakit untuk peningkatan kapasitas perawat dalam pemberian asuhan keperawatan $\Uparrow$ Mentoring ke-4 (penilaian akhir pembelajaran mentoring) dengan topik aplikasi teori keperawatan dalam pelayanan keperawatan di rumah sakit

Gambar 1. Proses Pembelajaran

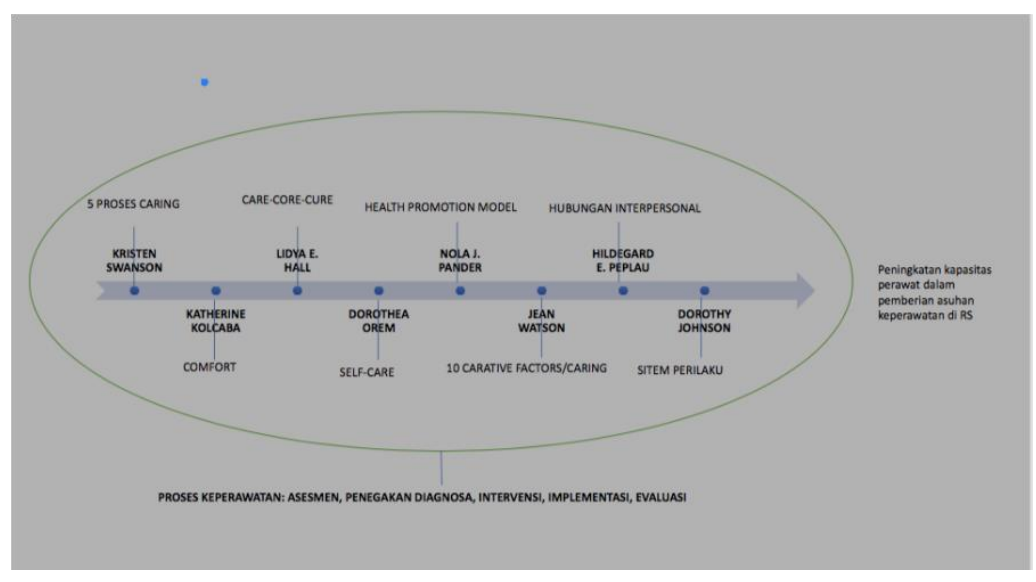

Gambar 2. Proses Keperawatan

\section{Desain Alat}

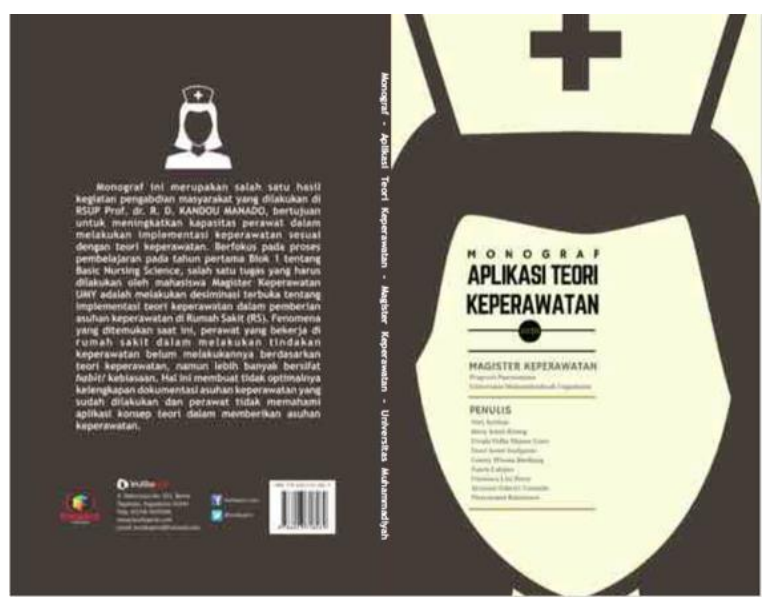

Gambar 3. Modul Materi 
1. Modul materi seminar (Monograf)

Modul materi seminar disusun sebagai salah satu media pembelajaran bagi peserta seminar. Isi modul ini meliputi:

a. Aplikasi teori kenyamanan Kolkaba di rumah sakit

b. Aplikasi teori Caring Swanson di rumah sakit

c. Implementasi teori Lydia E. Hall untuk peningkatan kualitas pelayanan keperawatan

d. Aplikasi Teori Hubungan Interpersonal di Rumah Sakit

e. Sistem Keperawatan Orem Bagi Pasien Medikal Bedah

f. Human Caring Theory Jean Watson

g. Teori Keperawatan Johnson

h. Teori Keperawatan Nola J. Pender

\section{Hasil dan Pembahasan}

\section{Lokasi dan waktu Pengabdian}

Pengabdian masyarakat ini dilakukan di RSUP. R.D Kandouw Manado, yang beralamat di Jl. Raya Tanawangko No. 56, Malalayang Satu Barat, Kec. Malalayang, Kota Manado, Sulawesi Utara bertempat di ruang sidang utama. Kegiatan dilaksanakan pada tanggal 27 Januari 2020, dibuka secara langsung oleh Direktur utama RSUP Dr. R.D Kandouw yang menyampaikan apresiasi atas inisiatif bagian diklat rumah sakit terutama keperawatan dalam penyelenggaraan mini seminar keperawatan. Tema yang diusung terkait aplikasi teori keperawatan di rumah sakit diharapkan mampu memberikan kontribusi dalam pengembangan keilmuan sehingga perawat mampu memberikan justifikasi atas tindakan keperawatan yang dilakukan. Direktur menyatakan keinginanya untuk melakukan kerjasama dengan UMY dalam pengembangan SDM keperawatan sehingga akan meningkatkan pelayanan keperawatan di rumah sakit.

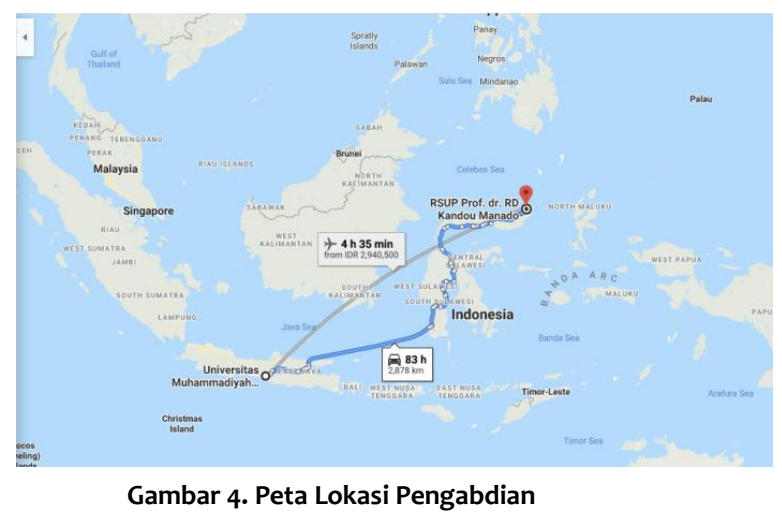

\section{Pelaksanaan Kegiatan}

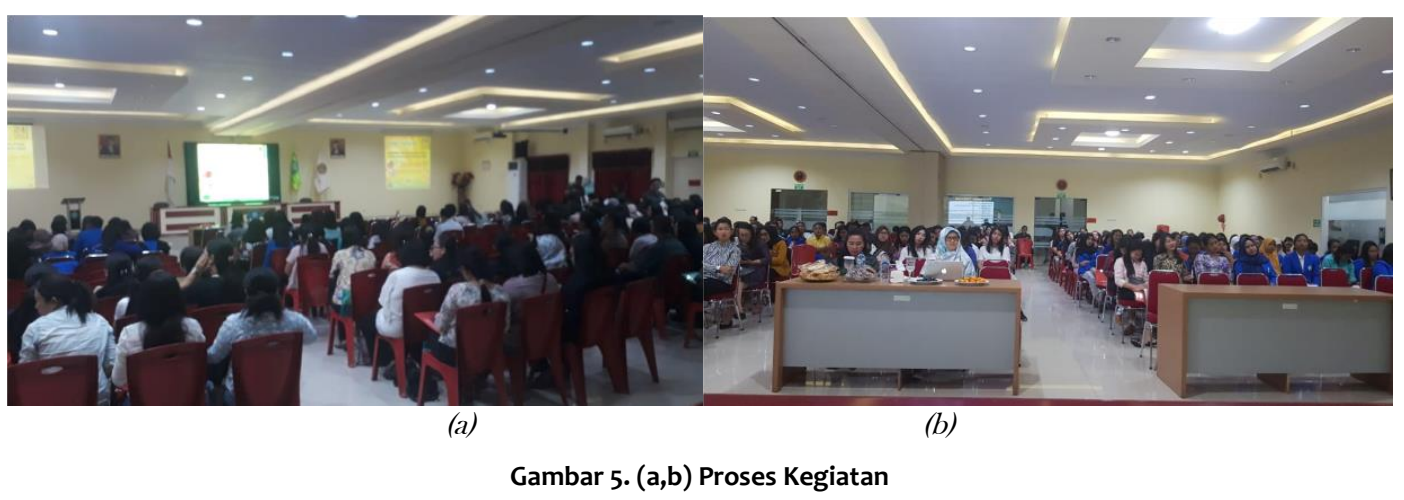


Pengabdian masyarakat ini dilaksanakan dalam 2 sesi, yaitu pagi dan siang yang terbagi atas 4 pembicara pagi dan 3 pembicara siang. Teori keperawatan yag disampaikan adalah:

a. Teori Comfort Kolkaba

b. Teori Caring Swanson

c. Teori Care, Core, Cure Lydia E. Hall

d. Teori Hubungan Interpersonal Hildegard Peplau

e. Teori Self Care Orem

f. Teori Caring Jean Watson

g. Teori Behavioral System Dorothy E Johnson

Masing-masing pembicara memiliki waktu maksimal 30 menit untuk mempresentasikan makalahnya dengan menggunakan power point presentation sebagai media komunikasi dengan peserta. Pelaksanaan seminar dapat berjalan dengan baik, terdapat sesi tanya jawab yang sangat aktif antara pembicara dan peserta. Peserta sebagian besar mampu memahami konsep model teori keperawatan yang telah disampaikan dan memahami pentingnya implementasi dalam proses pemberian asuhan keperawatan. Kegiatan seminar diakhiri dengan pemberian materi tentang pentingnya aplikasi teori keperawatan dalam asuhan keperawatan oleh Fitri Arofiati, sebagai penguatan konsep. Kegiatan seminar diakhiri pada jam 15.00

\section{Luaran Pengabdian masyarakat}

Publikasi hasil pengabdian masyarakat telah dilakukan di media massa Manado Post, media online. $\quad$ http://sulutaktual.com/2020/01/24/nursing-development-rsup-prof-kandou-rintiskerjasama-universitas-terakreditasi-a-prodi-magister-keperawatan/ http://www.voxsulut.com/2020/01/nursing-development-rsup-kandou-gelar.html
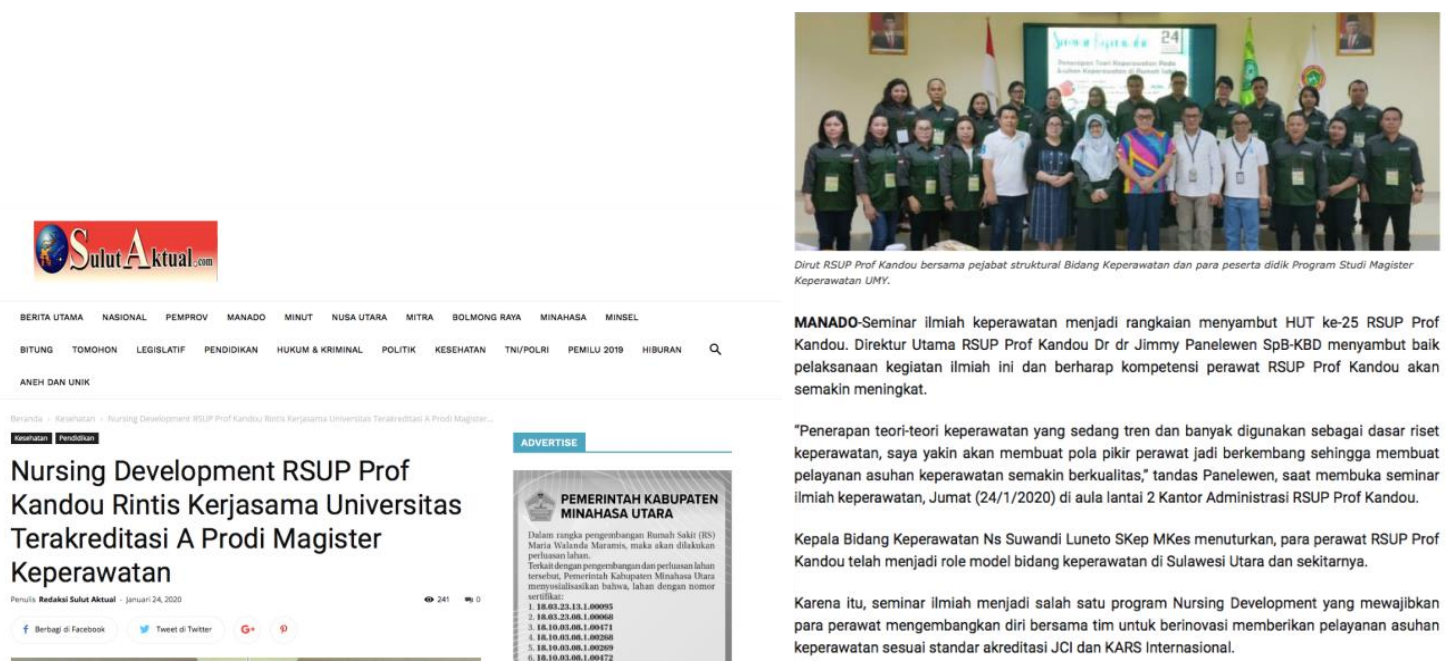

MANADO-Seminar ilmiah keperawatan menjadi rangkaian menyambut HUT ke-25 RSUP Prof Kandou. Direktur Utama RSUP Prof Kandou Dr dr Jimmy Panelewen SPB-KBD menyambut baik
pelaksanaan kegiatan ilmiah ini dan berharap kompetensi perawat RSUP Prof Kandou akan semakin meningkat.

"Penerapan teori-teori keperawatan yang sedang tren dan banyak digunakan sebagai dasar riset keperawatan, saya yakin akan membuat pola pikir perawat jadi berkembang sehingga membuat pelayanan asuhan keperawatan semakin berkualitas," tandas Panelewen, saat membuka seminar ilmiah keperawatan, Jumat (24/1/2020) di aula lantai 2 Kantor Administrasi RSUP Prof Kandou. Kepala Bidang Keperawatan Ns Suwandi Luneto SKep MKes menuturkan, para perawat RSUP Prof Kandou telah menjadi role model bidang keperawatan di Sulawesi Utara dan sekitarnya.

Karena itu, seminar illmiah menjadi salah satu program Nursing Development yang mewajibkan para perawat mengembangkan diri bersama tim untuk berinovasi memberikan pelayanan asuhan keperawatan sesuai standar akreditasi JCI dan KARS Internasional. 


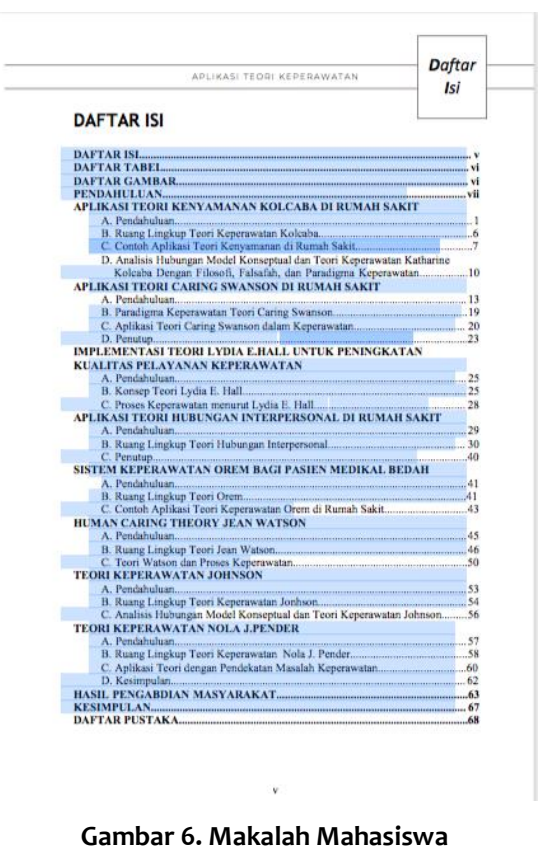

Makalah yang telah disusun oleh mahasiswa dibukukan dalam bentuk buku monograf ber-ISBN dengan nomor ISBN 9786023718269 dan diproses mendapatkan sertifikat HKI.

\section{Simpulan}

Pemberdayaan masyarakat yang terintegrasi proses pembelajaran dalam bentuk seminar ini mampu meningkatkan kompetensi pengetahuan peserta dalam implementasi teori keperawatan dalam pemberian asuhan keperawatan di RSUP. R.D Kandouw Manado

\section{Ucapan Terima Kasih}

Kami mengucapkan terima kasih kepada Rektor Universitas Muhammadiyah Yogyakarta, khususnya Kepala LP3M yang telah memberikan kesempatan dan pendanaan sehingga pengabdian masyarakat ini dapat terwujud. Ucapan terima kasih juga kami sampaikan kepada Direktur RSUP Dr. R.D Kandouw, Manado yang telah memberikan izin penggunaan sarana dan prasarana pelaksanaan pengabdian masyarakat. Tidak lupa pula kami mengucapkan terima kasih kepada Ketua Program Studi Magister Keperawatan yang juga telah memberikan izin dan diskusi konten pengabdian masyarakat yang dilakukan.

\section{DAFTAR PUSTAKA}

A. Davis Company. Patricia A, Potter, Anne G. Perry. (2009). Fundamental of Nursing, Seventh edition, St. Louis. Missouri : Mosby Elsevier.

Aini, N. (2018). Teori Model Keperawatan: Keperawatan (Vol. 1). UMMPPress

Alligood, Martha Raile. 2010. Nursing Theory : Utilization and Application. The United States of America: Mosby Elsevier.

Alligood, MR. 2014. Nursing Theorists and Their Work, Eight Edition. St Louis, Missouri: Elsevier Mosby.

Azwar \& Saifudin. (2011). Sikap Manusia Teori dan Pengukurannya. Yogyakarta. Pustaka Pelajar.

Peplau, H.E. Interpersonal Relation in Nursing. (1952). Buku Ajar Fundamental Keperawatan, POTTER and PERRY.

http://www.currentnursing.com/nursing.../interpersonal_theory.html. 28 Januari 2020. 
George, J. (2000), Care, Cure and Core: The Three C's of Lydia Hall. Nursing Theories: The Best for Professional Nursing Practice.

Gonzalo, A. (2011). Lydia E. Hall : Theoretical Foundations of Nursing. http://aindriblog.wordpress.com/2012/11/25/teori-dan- onsep- eperawatan- men!r!thildegard-e-pepla!/.

Johnson, D. E. (2011). Behavioral System Model. Nursing Theories: The Base for Professional Nursing Practice, 6/e, 146.

Kimball R, Hua Lee M, Summers S, (2012). Pioneer in Nursing Autonomy and Nurse-Driven Care : Lydia Hall

McKenna, Hugh. (1997). Nursing Theories and Models. New York: Routledge. Orem, D.E. 2001. Nursing Concept of Practiced. St. Louis: the CV Mosby Company.

Maureen, A. (2007). Middle Range Theory Development Using King's Conceptual System. New York: Springer Publishing Company.

Parker Marilyn E., Smith, \& Marlaine Cappelli. (2010). Nursing theories and nursing practice. 3rd ed. Philadelphia: F.

Peterson,Sandra J. \& Bredow, Timothy S. (2009). Middle Range Theories, Application to Nursing Research. Second edition. Philadelphia: Lippincott William \& Wilkins.

Potter, Patricia Ann . (2011). Basic Nursing. Missouri. Mosby Elsevier Sieloff, Christina Leibold and Frey.

Smith,Mary Jane \& Liehr, Patricia R. (2008). Middle range theory for nursing. 2nd ed. New York: Springer Publishing Company.

Tomey, A.M. \& Alligood, M.R.(2010). Nursing theorist and their work. Seventh edition. Published, St. Louis, Mo.: Mosby/Elsevier.

Tomey, Alligood. (2006). Nursing Theorist and Their Work. Sixth edition. Toronto: The CV Mosby Company St. Louis 